\title{
Association between apolipoprotein E4 and cognitive decline in elderly adults
}

Citation for published version (APA):

Packard, C. J., Westendorp, R. G. J., Stott, D. J., Caslake, M. J., Murray, H. M., Sheperd, J., Blauw, G. J., Murphy, M. B., Bollen, E. L., Buckley, B. M., Cobbe, S., Ford, I., Gaw, A., Hyland, M., Jukema, J. W., Kamper, A. M., Macfarlane, P. W., Jolles, J., Perry, IJ., ... Twomey, C. (2007). Association between apolipoprotein E4 and cognitive decline in elderly adults. American Journal of Geriatric Psychiatry, 55(11), 1777-1785. https://doi.org/10.1111/j.1532-5415.2007.01415.x

Document status and date:

Published: 01/01/2007

DOI:

10.1111/j.1532-5415.2007.01415.x

Document Version:

Publisher's PDF, also known as Version of record

\section{Please check the document version of this publication:}

- A submitted manuscript is the version of the article upon submission and before peer-review. There can be important differences between the submitted version and the official published version of record.

People interested in the research are advised to contact the author for the final version of the publication, or visit the DOI to the publisher's website.

- The final author version and the galley proof are versions of the publication after peer review.

- The final published version features the final layout of the paper including the volume, issue and page numbers.

Link to publication

\footnotetext{
General rights rights.

- You may freely distribute the URL identifying the publication in the public portal. please follow below link for the End User Agreement:

www.umlib.nl/taverne-license

Take down policy

If you believe that this document breaches copyright please contact us at:

repository@maastrichtuniversity.nl

providing details and we will investigate your claim.
}

Copyright and moral rights for the publications made accessible in the public portal are retained by the authors and/or other copyright owners and it is a condition of accessing publications that users recognise and abide by the legal requirements associated with these

- Users may download and print one copy of any publication from the public portal for the purpose of private study or research.

- You may not further distribute the material or use it for any profit-making activity or commercial gain

If the publication is distributed under the terms of Article $25 \mathrm{fa}$ of the Dutch Copyright Act, indicated by the "Taverne" license above, 


\title{
Association Between Apolipoprotein $\mathrm{E}_{4}$ and Cognitive Decline in Elderly Adults
}

\author{
Chris J. Packard, DSc, ${ }^{a}$ Rudi G.J. Westendorp, MD, ${ }^{d}$ David J. Stott, MD, ${ }^{b}$ Muriel J. Caslake, PhD, ${ }^{a}$ \\ Heather M. Murray, MSc, ${ }^{c}$ James Shepherd, MD, ${ }^{g}$ Gerard J. Blauw, MD, ${ }^{d}$ Michael B. Murphy, MD, ${ }^{g}$ \\ Edward L.E.M. Bollen, MD, ${ }^{l}$ Brendan M. Buckley, MD, ${ }^{g}$ Stuart M. Cobbe, MD, ${ }^{b}$ Ian Ford, PhD, ${ }^{c}$ Allan \\ Gaw, MD, ${ }^{k}$ Michael Hyland, MD, ${ }^{b}$ J. Wouter Jukema, $M D,{ }^{m}$ Adriaan M. Kamper, $M D,{ }^{d}$ Peter W. \\ Macfarlane, DSc, Jellemer Jolles, MD, ${ }^{e, f}$ Ivan J. Perry, MD, ${ }^{i}$ Brian J. Sweeney, ${ }^{j}$ and Cillian Twomey, \\ $M D^{b}$ for the Prospective Study of Pravastatin in the Elderly at Risk Group
}

OBJECTIVE: To determine the influence of apolipoprotein $\mathrm{E}$ on cognitive decline in a cohort of elderly men and women. DESIGN: Prospective study.

SETTING: Scotland, Ireland, and the Netherlands.

PARTICIPANTS: Five thousand eight hundred four subjects aged 70 to 82 from the Prospective Study of Pravastatin in the Elderly at Risk (PROSPER).

MEASUREMENTS: Subjects were assessed at baseline and over a mean 3.2-year (range 0.7-4.2) follow-up for memory (Picture-Word Recall), speed of information processing (Stroop and Letter-Digit Coding), global cognitive function (Mini-Mental State Examination), and activities of daily living.

RESULTS: At baseline, subjects with apolipoprotein $\mathrm{E}_{4}$ versus those without $\mathrm{E}_{4}$ had poorer memory performance (mean score difference $-0.20 \quad(95 \%$ confidence interval $(\mathrm{CI})=-0.31$ to -0.09$)$ for immediate recall and -0.32 $(95 \% \mathrm{CI}=-0.48$ to -0.16$)$ for delayed recall and slower information processing (difference in Stroop, 2.79 seconds, $(95 \%$ CI $=1.20-4.28)$; Letter-Digit score, -0.36 , $(95 \%$ $\mathrm{CI}=-0.77-0.05)$. Subjects with apolipoprotein $\mathrm{E}_{4}$ showed a greater decline in immediate $(-0.22,95 \% \mathrm{CI}=-0.33$ to $-0.11)$ and delayed $(-0.30,95 \% \mathrm{CI}=-0.46$ to -0.15$)$

From the a Department of Vascular Biochemistry, ${ }^{\mathrm{b}}$ Division of Cardiovascular and Medical Sciences, and ${ }^{c}$ Robertson Centre for Biostatistics, University of Glasgow, Glasgow, Scotland; 'Section of Gerontology and Geriatrics, Leiden University Medical Center, Leiden, The Netherlands; Departments of ${ }^{\mathrm{e}}$ Psychiatry and ${ }^{\mathrm{f}}$ Neuropsychology, Maastricht University, Maastricht, The Netherlands; Departments of ${ }^{\mathrm{g} P h a r m a c o l o g y}$ and Therapeutics, ${ }^{\mathrm{h}}$ Geriatric Medicine, ${ }^{\mathrm{i}}$ Epidemiology and Public Health, and ${ }^{\mathrm{j}}$ Neurology, Cork University Hospital, Cork, Ireland; ${ }^{k}$ North Glasgow Operating Division, National Health Service Greater Glasgow and Clyde, Glasgow, Scotland; and Departments of ${ }^{\mathrm{l}}$ Neurology and ${ }^{\mathrm{m}}$ Cardiology, Leiden University Medical Centre, Leiden, The Netherlands.

Address correspondence to Professor Chris J. Packard, Department of Vascular Biochemistry, 4th Floor University Block, Glasgow Royal Infirmary, Glasgow G31 2ER. E-mail: chris.packard@clinmed.gla.ac.uk

DOI: $10.1111 / \mathrm{j} .1532-5415.2007 .01415 . \mathrm{x}$ memory scores but no significant change in speed of information processing (Stroop, $P=.17$; Letter-Digit, $P=.06)$. Memory scores decreased $2.5 \%$ from baseline in those without $\mathrm{E}_{4}, 4.3 \%$ in $\mathrm{E}_{4}$ heterozygotes $(P=.01$ for immediate and $P=.03$ for delayed, vs no $\left.\mathrm{E}_{4}\right)$ and $8.9 \%$ to $13.8 \%$ in $\mathrm{E}_{4}$ homozygotes $(P=.04$ for immediate and $P=.004$ for delayed, vs heterozygotes). Apolipoprotein $\mathrm{E}_{4}$ was associated with greater decline in instrumental activities of daily living $(P<.001)$. Cognitive decline was not associated with lipoprotein levels.

CONCLUSION: Findings in PROSPER indicate that $\mathrm{E}_{4}$ is associated with more-rapid cognitive decline and may, therefore, predispose to dementia. J Am Geriatr Soc 55:1777-1785, 2007.

Key words: memory; dementia; trial; statin
A major challenge in the quest to promote healthy aging is to uncover the determinants of cognitive decline in the general population and the risk factors that lead to the development of frank dementia. Although age is the main predictor of cognitive function, investigators have also re- ported that a history of hypertension, diabetes mellitus, stroke, depression, and lack of physical activity are fac- tors. ${ }^{1-6}$ The apolipoprotein E phenotype (apolipoprotein E is coded by a gene $(\varepsilon)$ that exhibits allelic variants $\varepsilon_{2}, \varepsilon_{3}$, and $\varepsilon_{4}$ ) has been linked consistently and strongly to the appear- ance of Alzheimer's disease and to some aspects of cognitive decline in elderly cohorts. ${ }^{1,2,5-9}$ Inheritance of $\mathrm{E}_{4}$ (the prod- uct of $\varepsilon_{4}$ ) especially in the homozygous form, has been as- sociated in cross-sectional studies with risk of Alzheimer's disease and poorer global cognitive function, episodic memory, and executive function, although the magnitude of the effect is modest. ${ }^{10,11}$ Longitudinal data also show good evidence of an association between $\mathrm{E}_{4}$ and risk of Alzheimer's disease and dementia, ${ }^{12,13}$ although the rela- 
tionship between the $\mathrm{E}_{4}$ genotype and age-associated cognitive decline without dementia has been less clear. ${ }^{14}$ One study ${ }^{15}$ found a link in twins between $\mathrm{E}_{4}$ and deterioration of working memory, and others have reported greater decline in verbal memory and executive function in those with $\mathrm{E}_{4}{ }^{16-18}$ In contrast, another study ${ }^{13}$ found that possession of $\mathrm{E}_{4}$ did not modify progression of cognitive decline in the preclinical period of Alzheimer's disease, and a third study ${ }^{19}$ reported slower rates of memory decline in $\mathrm{E}_{4}$ carriers. Likewise, it was found that $\mathrm{E}_{4}$ did not contribute to prediction of cognitive decline in the very old but that cerebrovascular disease was a major risk factor for this and for progression to dementia. ${ }^{20}$ It is important, therefore, to widen the evidence base for the effects of $\mathrm{E}_{4}$ on cognitive decline before the appearance of dementia to assess how early this genetic variation has an effect. The role of apolipoprotein $\mathrm{E}$ in brain physiology and the precise nature of the influence of the phenotypic variation on the pathogenesis of neurodegenerative disease is unknown, although clues are emerging from molecular studies ${ }^{21}$ and from investigations of white matter structure. ${ }^{22}$

The nature of the association between lipid and lipoprotein levels and cognitive impairment is largely unknown, with conflicting results being reported. ${ }^{23-26}$ Recently, low highdensity lipoprotein cholesterol (HDL-C) levels have been linked to poorer cognitive function, independent of an effect on cardiovascular disease in the oldest old, ${ }^{23}$ whereas no association between total plasma cholesterol or HDL-C and risk of Alzheimer's disease was observed in another study. ${ }^{26}$

The Prospective Study of Pravastatin in the Elderly at Risk (PROSPER) was a trial of statin use for the prevention of cardiovascular and cerebrovascular disease in 5,804 men and women aged 70 to $82 .{ }^{27}$ It demonstrated that pravastatin treatment was associated with a reduction in vascular events. Part of the trial design was to examine the effect of statin therapy on cognition. To this end, a battery of cognitive function tests was administered at baseline and annually during follow-up ${ }^{28}$ and linked to initial lipid levels, apolipoprotein $\mathrm{E}$ phenotype, and treatment allocation. It was reported previously that pravastatin use did not affect cognitive decline. ${ }^{27}$ Here, the effect of apolipoprotein $\mathrm{E}$ phenotype and lipoprotein levels on cognitive function at baseline and on cognitive decline are described in this large cohort. On the basis of previous work in smaller studies and the role of vascular disease in dementia, the working hypothesis was that apolipoprotein $\mathrm{E}$ phenotype and levels of low-density lipoprotein cholesterol (LDL-C) and HDL-C would influence cognition. ${ }^{29-31}$

\section{METHODS}

\section{Study Design and Subjects}

PROSPER was a trial of statin use in preventing coronary and cerebrovascular events in older subjects with a history of vascular disease or at high risk of an event due to a history of smoking, hypertension, or diabetes mellitus. ${ }^{32}$ A total of 5,804 individuals (2,804 men, 3,000 women; aged 70-82) were recruited in Scotland, Ireland, and the Netherlands and randomized to receive $40 \mathrm{mg} / \mathrm{d}$ pravastatin or placebo daily. Follow-up was for 3.2 years on average (range 0.7-4.2 years). As part of the design of the study, whether statin treatment had any effect on cognitive decline was assessed by administering a battery of cognitive function tests. ${ }^{28}$ Determinants of cognitive function at baseline and of cognitive decline were sought from the risk factor profiles, including apolipoprotein E phenotype, which was assessed during screening. There were restrictions on entry; plasma cholesterol had to be in the range of 4.0 to $9.0 \mathrm{mmol} / \mathrm{L}$ and plasma triglyceride less than $6.0 \mathrm{mmol} / \mathrm{L}$. The institutional ethics review boards of the centers approved the study, and all participants gave written informed consent.

\section{Measurements}

Plasma cholesterol, triglyceride, LDL-C, and HDL-C were measured twice at fasting visits during the placebo run-in phase according to the Lipid Research Clinics protocol ${ }^{33}$ in a central laboratory that was standardized through the Centers for Disease Control and Prevention network. Apolipoprotein E phenotype was determined on plasma samples using Western blotting following a method previously established. ${ }^{34}$ Subjects were classified according to the presence of the $\mathrm{E}_{2}, \mathrm{E}_{3}$, or $\mathrm{E}_{4}$ bands on gel blots. The gel phenotyping method shows high concordance (>95\%) with genotype testing according to allele-specific oligonucleotide assay (unpublished results).

A detailed description of the cognitive tests used in the study has been published previously. ${ }^{28}$ The Mini-Mental State Examination (MMSE) is used widely to screen for cognitive impairment and dementia. ${ }^{35}$ A cutoff score of 24 points or more (out of 30) was used as an inclusion criterion to eliminate those with poor cognitive function at baseline. Memory was tested using the Picture-Word Recall test based on the Groningen-Fifteen Words test. ${ }^{28,36}$ This measures recall, both immediate and after 20 minutes, of 15 pictures (rather than words, to overcome any language problem). The outcome variable is the mean number of correctly recalled pictures over three immediate trials and number recalled after the delay. Attention and processing were assessed using the Stroop-Color Word test ${ }^{37}$ and the Letter-Digit Coding test. ${ }^{28}$ The former, in the key Part III of the test, presents color names printed in incongruously colored ink (e.g., the word green printed in blue ink). Performance, timed in seconds to complete the test, measures the ability to discard the irrelevant name (green) in favor of the color of the ink (blue). The latter asks the subject to fill in digits next to letters according to a key; the outcome is the number of correct entries in 60 seconds. Subjects were assessed twice ( 2 weeks apart) at baseline to allow for any training effect. The results of the second test were taken as the starting estimate of cognitive function. Decline in basic activities of daily living (ADLs) was assessed using the 20-point variation ${ }^{38}$ of the Barthel Index ${ }^{39}$ and in extended activities instrumental activities of daily living (IADLs) using a 14-point score. ${ }^{40}$ All tests were repeated at 9,18 , and 30 months and at the final trial visit. Dementia was recorded as an adverse event if diagnosed by an attending physician; no trial-specific assessment was performed, and it was not an adjudicated endpoint.

\section{Statistical Analyses}

Subjects were divided initially into three categories $\left(\mathrm{E}_{4}+\right.$ (phenotypes $\mathrm{E}_{3 / 4}, \mathrm{E}_{2 / 4}$, and $\mathrm{E}_{4 / 4}$ ), $\mathrm{E}_{3 / 3}$ (the common- 
est phenotype), and $\mathrm{E}_{2}+$ (phenotypes $\mathrm{E}_{2 / 3}$ and $\left.\mathrm{E}_{2 / 2}\right)$ ) to test for an effect of phenotype on cognition. No significant difference was seen in any result between $\mathrm{E}_{3 / 3}$ and $\mathrm{E}_{2}+$ subjects, and these were combined into an $\mathrm{E}_{4}$ - category. Baseline characteristics were compared between the $\mathrm{E}_{4}+$ and $\mathrm{E}_{4}$ - groups using two-sample $t$-tests for continuous variables and the chi-square test for categorical variables. As part of this demographic assessment, overall risk of stroke was estimated as described previously ${ }^{41}$ and the computed risk was compared between $\mathrm{E}_{4}+$ and $\mathrm{E}_{4}-$ subjects. Cognitive measures at baseline and decline in cognition were compared between phenotype categories using linear models adjusted for age, sex, country, educational attainment, history of vascular disease, history of myocardial infarction, history of stroke or transient ischemic attack, smoking, use of antihypertension medication, blood pressure, body mass index, history of diabetes mellitus, triglyceride and lipoprotein cholesterol levels, and where appropriate, version of test used. Models for change in cognitive function from baseline (referred to as cognitive decline) were also adjusted for treatment allocation and baseline test scores. Adjusted least square means and standard errors are reported for each of the three original phenotype categories, and mean differences with $95 \%$ confidence intervals (CIs) and $P$-values are given for the $\mathrm{E}_{4}+$ and $\mathrm{E}_{4}-$ groups. Cognitive decline was defined as the difference between subjects' last recorded follow-up measurement and the second of two baseline measurements. In further analyses, only subjects with MMSE scores of 26 to 30 were included ( $\mathrm{n}=5,295)$. Time to dementia (as a recorded adverse event), or in a separate analysis to an MMSE score less than 24, in the $\mathrm{E}_{4}+$ and $\mathrm{E}_{4}$ - groups was estimated using Cox proportional hazard models. Kaplan-Meier curves were generated for incident dementia in the $\mathrm{E}_{4}+$ and $\mathrm{E}_{4}-$ groups.

The $\mathrm{E}_{4}+$ group was split into $\mathrm{E}_{4}$ homozygotes $\left(\mathrm{E}_{4 / 4}\right)$ and $E_{4}$ heterozygotes $\left(E_{2 / 4}\right.$ and $\left.E_{3 / 4}\right)$. Mean results of cognition tests at baseline, and of cognitive decline, were compared between these phenotypes and the $\mathrm{E}_{4}-$ group. Results were also analyzed as percentage change over baseline. An average percentage decline in memory function was calculated from the results of the immediate and delayed Picture-Word recall. This variable was then compared in $\mathrm{E}_{4}-, \mathrm{E}_{4}$ heterozygotes, and $\mathrm{E}_{4}$ homozygotes in subjects with baseline MMSE scores of 24 to 30 (evaluable subjects, $\mathrm{n}=5,004), 26$ to $30(\mathrm{n}=4,611)$, and $28-30(\mathrm{n}=3,456)$.

Repeated-measures models that included all of the measurements recorded on a subject and incorporated a linear separation between the groups were investigated, although these more-complex models did not add statistical power, possibly because of the additional assumptions made being invalid. This approach is not reported here; rather the simpler change from baseline analysis was used.

To examine the association between cognition and LDL-C and HDL-C, linear models were constructed as for apolipoprotein $\mathrm{E}$ analysis. For descriptive purposes, least squares means and standard errors adjusted for baseline variables, as noted previously, as well as apolipoprotein $\mathrm{E}_{4}$ status, are given for tertiles of LDL-C and HDL-C. $P$-values for continuous measures of HDL-C and LDL-C are also reported.

For all analyses, only complete and reliable test results of cognitive function (as indicated by the study nurse who administered the test) were included.

\section{RESULTS}

Of the 5,804 subjects recruited to the study, apolipoprotein E phenotyping was available for $95.5 \% ; 38(0.7 \%)$ were $\mathrm{E}_{2 / 2}$, $621(11.2 \%)$ were $\mathrm{E}_{2 / 3}, 119(2.2 \%)$ were $\mathrm{E}_{2 / 4}, 3,496(63.1 \%)$ were $\mathrm{E}_{3 / 3}, 1,169(21.1 \%)$ were $\mathrm{E}_{3 / 4}$, and $101(1.8 \%)$ were $\mathrm{E}_{4 / 4}$. Translated into genotypes, the frequencies were in HardyWeinberg equilibrium. Thus, a total of 4,155 subjects were classified as $\mathrm{E}_{4}-$ and 1,389 as $\mathrm{E}_{4}+$. In univariate analysis, the latter group had higher plasma total cholesterol (mean \pm standard deviation $5.84 \pm 0.91$ vs $5.63 \pm 0.90 \mathrm{mmol} / \mathrm{L}, P<.001$ ), higher LDL-C $(3.96 \pm 0.81$ vs $3.74 \pm 0.79 \mathrm{mmol} / \mathrm{L}, P<$ $.001)$, lower HDL-C $(1.25 \pm 0.34$ vs $1.29 \pm 0.35 \mathrm{mmol} / \mathrm{L}$, $P<.001)$, and higher plasma triglyceride $(1.60 \pm 0.75$ vs $1.52 \pm 0.68 \mathrm{mmol} / \mathrm{L}, P<.001)$ levels than the former. No significant difference was observed in blood pressure; sex; history of coronary disease, stroke, or hypertension; smoking habit; years of education; or a composite score of stroke risk. ${ }^{41}$ Subjects with diabetes mellitus were approximately $25 \%$ less prevalent in the $\mathrm{E}_{4}+$ group $(P=.007)$. Subjects who were $\mathrm{E}_{4}+$ were marginally younger than those who were $\mathrm{E}_{4}-$.

At baseline, age, sex, and educational status were major determinants of all tests of cognitive function. History of stroke, diabetes mellitus, and smoking were predictors of scores in the Stroop and Letter-Digit Coding tests but not of memory function (i.e., immediate and delayed Picture-Word Recall). History of vascular disease, history of stroke, body mass index, diabetes mellitus, and smoking were predictors of scores in the Barthel and IADL indices (data not shown).

\section{Influence of Apolipoprotein E Phenotype}

Apolipoprotein E phenotype had a significant association with a number of tests of cognitive function, determined upon entry into the study (Table 1). As discussed in the Methods section, none of the $\mathrm{E}_{2}+$ versus $\mathrm{E}_{3 / 3}$ comparisons indicated a significant difference, and these phenotypes were combined in the $\mathrm{E}_{4}-$ category. Subjects in the $\mathrm{E}_{4}+$ group performed significantly less well on the Stroop test and Picture-Word Recall (immediate and delayed) than subjects in the $\mathrm{E}_{4}-$ group and had marginally, but significantly, poorer scores on the MMSE (Table 1). No significant influence of apolipoprotein $\mathrm{E}_{4}$ status was seen for the Letter-Digit Coding test or the Barthel or IADL indices. Restricting the analyses to subjects with baseline MMSE scores of 26 to 30 did not alter these associations (data not shown).

Follow-up assessments on at least one of the cognitive tests were available for $98.4 \%(5,454 / 5,544)$ of subjects with apolipoprotein E phenotyping available, and 4,942 completed at least 3 years of assessment. Of the 90 subjects without any follow-up assessment, 72 died, 11 refused to participate or did not attend a follow up cognitive assessment, and seven had a nonfatal adverse event. Over the average 3.2 years (range 0.7-4.2 years) of follow-up, apolipoprotein $\mathrm{E}_{4}$ status significantly influenced change in scores on the cognitive tests associated with memory (immediate and delayed Picture-Word Recall) but not those for attention and processing (Stroop, Letter-Digit Coding) (Table 2). Again, none of the comparisons between $E_{3 / 3}$ and $\mathrm{E}_{2}+$ subjects was significant. Those in the $\mathrm{E}_{4}+$ group had significantly greater decrements than those in the $\mathrm{E}_{4}$ - group on MMSE, Barthel, and IADL scores. At the 
Table 1. Comparison of Baseline Measures of Cognition According to Apolipoprotein E Phenotype

\begin{tabular}{|c|c|c|c|}
\hline $\begin{array}{c}\text { Cognitive } \\
\text { Test and } \\
\text { Apolipoprotein } \\
\text { E Phenotype* }\end{array}$ & $\begin{array}{c}\text { Baseline, } \\
\text { Least Square } \\
\text { Mean (Standard } \\
\left.\text { Error }^{\dagger}\right)\end{array}$ & $\begin{array}{c}E_{4}+\text { versus } \\
E_{4}-\text { Mean Difference } \\
\text { (95\% Confidence } \\
\text { Interval })^{\ddagger}\end{array}$ & $P$-Value ${ }^{\ddagger}$ \\
\hline \multicolumn{4}{|c|}{ Stroop Part III (seconds to complete) $(n=5,163)$} \\
\hline $\mathrm{E}_{4}+$ & $71.1(0.93)^{\S}$ & $2.79(1.30,-4.28)$ & $<.001$ \\
\hline$E_{3} / 3$ & $68.3(0.77)$ & & \\
\hline $\mathrm{E}_{2}+$ & $68.1(1.17)$ & & \\
\hline \multicolumn{4}{|c|}{ Letter-Digit Coding (number correct) $(n=5,185)$} \\
\hline $\mathrm{E}_{4}+$ & $22.1(0.26)$ & $-0.36(0.77,-0.05)$ & .08 \\
\hline$E_{3} / 3$ & $22.5(0.21)$ & & \\
\hline $\mathrm{E}_{2}+$ & $22.5(0.32)$ & & \\
\hline \multicolumn{4}{|c|}{ Picture-Word Recall (number recalled) $(n=5,222)$} \\
\hline \multicolumn{4}{|c|}{ Immediate } \\
\hline $\mathrm{E}_{4}+$ & $9.16(0.07)^{\S}$ & $-0.20(-0.31,-0.09)$ & $<.001$ \\
\hline$E_{3} / 3$ & $9.35(0.06)$ & & \\
\hline $\mathrm{E}_{2+}$ & $9.44(0.09)$ & & \\
\hline \multicolumn{4}{|l|}{ Delayed } \\
\hline$E_{4}+$ & $9.77(0.10)^{\S}$ & $-0.32(-0.48,-0.16)$ & $<.001$ \\
\hline$E_{3} / 3$ & $10.07(0.08)$ & & \\
\hline$E_{2}+$ & $10.24(0.12)$ & & \\
\hline \multicolumn{4}{|c|}{ Barthel Index (score) $(n=5,544)$} \\
\hline $\mathrm{E}_{4}+$ & $19.6(0.03)$ & $-0.04(-0.08,-0.00)$ & .08 \\
\hline$E_{3} / 3$ & $19.6(0.02)$ & & \\
\hline $\mathrm{E}_{2}+$ & $19.7(0.03)$ & & \\
\hline \multicolumn{4}{|c|}{ Instrumental activity of daily living index (score) $(n=5,544)$} \\
\hline $\mathrm{E}_{4}+$ & $13.4(0.04)$ & $-0.05(-0.11,-0.01)$ & .12 \\
\hline $\mathrm{E}_{3} / 3$ & $13.4(0.03)$ & & \\
\hline $\mathrm{E}_{2+}$ & $13.4(0.05)$ & & \\
\hline \multicolumn{4}{|c|}{ Mini-Mental State Examination (score) $(n=5,479)$} \\
\hline $\mathrm{E}_{4}+$ & $27.8(0.06)^{\S}$ & $-0.21(-0.30,-0.12)$ & $<.001$ \\
\hline$E_{3} / 3$ & $28.0(0.05)$ & & \\
\hline$E_{2}+$ & $28.0(0.07)$ & & \\
\hline
\end{tabular}

* $\mathrm{E}_{4}+$ includes $\mathrm{E}_{4} / 4, \mathrm{E}_{4} / 3$, and $\mathrm{E}_{4} / 2$ phenotypes, $\mathrm{E}_{2}+$ includes $\mathrm{E}_{3} / 2$ and $\mathrm{E}_{2} / 2$. ${ }^{\dagger}$ Adjusted for age, sex, country, education, history of vascular disease, history of myocardial infarction, history of diabetes mellitus, history of stroke or transient ischemic attack, smoking, use of antihypertensive medication, blood pressure, body mass index, low-density lipoprotein cholesterol, high-density lipoprotein cholesterol, triglyceride, and where applicable test version.

${ }^{\ddagger}$ Comparison of mean test results in $\mathrm{E}_{4}+\left(\mathrm{E}_{4 / 4}, \mathrm{E}_{4 / 2}, \mathrm{E}_{4 / 3}\right)$ subjects versus $\mathrm{E}_{4}-$ $\left(\mathrm{E}_{3 / 3}, \mathrm{E}_{2 / 3}, \mathrm{E}_{2 / 2}\right)$ subjects.

$\S_{\text {Apolipoprotein }} \mathrm{E}_{4}+$ group result was significantly different from $E_{3 / 3}$ and $\mathrm{E}_{2}+$ result.

end of the study, $85(6.4 \%)$ in the $\mathrm{E}_{4}+$ group and 131 $(3.3 \%)$ in the $\mathrm{E}_{4}-$ group had scores less than 24 on the MMSE $(P<.001$ for difference in incidence), and there were 37 cases of dementia reported as an adverse event $(2.7 \%)$ in the $\mathrm{E}_{4}+$ group and $46(1.1 \%)$ in the $\mathrm{E}_{4}-$ group, a 2.48 -fold difference in risk $(P<.001)$. Including only those with MMSE scores of 26 to 30 at baseline produced the same qualitative result (data not shown).

Treatment assignment (i.e., to placebo or pravastatin therapy) was included in the multivariate models. It was reported previously that pravastatin use during the trial had no significant effect on change in cognitive function. ${ }^{42}$ This was further tested by examining the interaction between
Table 2. Comparison of Change in Cognitive Function According to Apolipoprotein E Phenotype

\begin{tabular}{|c|c|c|}
\hline $\begin{array}{l}\text { Cognitive Test and } \\
\text { Apolipoprotein E } \\
\text { Phenotype* }\end{array}$ & $\begin{array}{c}\text { Change, Least } \\
\text { Square Mean } \\
\text { (Standard } \\
\text { Error) })^{\dagger}\end{array}$ & $\begin{array}{c}\mathrm{E}_{4}+\text { versus } \mathrm{E}_{4}- \\
\text { Mean Difference } \\
(95 \% \text { Confidence } \\
\text { Interval) }\end{array}$ \\
\hline
\end{tabular}

Stroop Part III (seconds to complete) $(n=4,897)^{\S}$

$\begin{array}{cccc}\mathrm{E}_{4}+ & +5.99(0.85) & +0.95(0.39-2.29) & .17 \\ \mathrm{E}_{3} / 3 & +5.02(0.70) & & \\ \mathrm{E}_{2}+ & +5.14(1.06) & & \\ \text { Letter-Digit Coding (number correct) }(n=4,953) & & \\ \mathrm{E}_{4}+ & -1.88(0.18) & -0.26(0.53-0.01) & .06 \\ \mathrm{E}_{3} / 3 & -1.60(0.14) & & \\ \mathrm{E}_{2}+ & -1.77(0.21) & \end{array}$

Picture Word Recall (number recalled) $(n=5,004)$

Immediate

$\begin{array}{cccc}E_{4}+ & -0.52(0.068)^{\| \#} & -0.22(0.33,-0.11) & <.001 \\ E_{3} / 3 & -0.30(0.056) & & \\ E_{2}+ & -0.31(0.085) & & \\ \text { Delayed } & & & \\ E_{4}+ & -0.82(0.098)^{\|} & -0.30(0.46,-0.15) & <.001 \\ E_{3} / 3 & -0.51(0.080) & & \\ E_{2}+ & -0.58(0.121) & & \\ \text { Barthel Index (score) }(n=5,453) & & \\ E_{4}+ & -0.63(0.068)^{\|} & -0.13(0.24,-0.02) & .02 \\ E_{3} / 3 & -0.51(0.056) & & \\ E_{2}+ & -0.48(0.086) & & \end{array}$

Instrumental activity of daily living index (score) $(n=5,454)$

\begin{tabular}{cccc}
$\mathrm{E}_{4}+$ & $-1.20(0.082)^{\| \#}-0.32(0.45,-0.18)$ & $<.001$ \\
$\mathrm{E}_{3} / 3$ & $-0.89(0.068)$ & & \\
$\mathrm{E}_{2}+$ & $-0.87(0.10)$ & \\
Mini-Mental State Examination $(\mathrm{score})(\mathrm{n}=5,260)$ & \\
$\mathrm{E}_{4}+$ & $-0.42(0.072)^{\| \#}-0.27(0.39,-0.16)$ & $<.001$ \\
$\mathrm{E}_{3} / 3$ & $-0.15(0.060)$ & \\
$\mathrm{E}_{2}+$ & $-0.12(0.091)$ & \\
\hline
\end{tabular}

${ }^{*} \mathrm{E}_{4}+$ includes $\mathrm{E}_{4 / 4}, \mathrm{E}_{4 / 3}, \mathrm{E}_{4 / 2} ; \mathrm{E}_{2}+$ includes $\mathrm{E}_{2 / 3}, \mathrm{E}_{2 / 2}$.

${ }^{\dagger}$ Change score (last recorded result minus baseline result) adjusted for age, sex, country, education, history of vascular disease, history of myocardial infarction, history of diabetes mellitus, history of stroke or transient ischemic attack, smoking, use of antihypertensive medication, blood pressure, body mass index, low-density lipoprotein cholesterol, high-density lipoprotein cholesterol, triglyceride, and where applicable test version, plus baseline test score and treatment allocation.

${ }^{\ddagger}$ Comparison of mean change in $\mathrm{E}_{4}+$ and $\mathrm{E}_{4}$ - groups.

${ }^{\S} \mathrm{A}$ positive change in the Stroop test indicates deteriorating performance.

"Apolipoprotein $\mathrm{E}_{4}+$ group result was significantly different from $\mathrm{E}_{3 / 3}$ result.

${ }^{\#}$ Apolipoprotein $\mathrm{E}_{4}+$ group result was significantly different from $\mathrm{E}_{2}+$ result.

apolipoprotein E phenotype, treatment, and cognition. No significant associations were found with any of the tests, confirming the lack of effect of statin therapy on cognitive decline (data not shown).

\section{Gene Dose Effect}

Further analyses were performed in which $\mathrm{E}_{4}$ homozygotes were considered separately from $\mathrm{E}_{4}$ heterozygotes (Table 3 ). At baseline, neither $\mathrm{E}_{4}$ homozygotes nor $\mathrm{E}_{4}$ heterozygotes differed from $\mathrm{E}_{4}-$ on the Letter-Digit Coding test or on the 
Table 3. Apolipoprotein E4 Status and Cognitive Function

$$
E_{4}-(N=4,155)^{*} \quad E_{4} \text { Heterozygotes }(N=1,288)^{*} \quad E_{4} \text { Homozygotes }(N=101)^{*}
$$

Cognitive Test

Least Square Mean (Standard Error)

P-Value

\begin{tabular}{|c|c|c|c|c|}
\hline \multicolumn{5}{|c|}{ Stroop Part III (seconds to complete) ${ }^{\ddagger}$} \\
\hline Baseline $(n=5,163)$ & $68.3(0.75)$ & $71.1(0.95)^{\S}$ & $70.1(2.52)$ & .001 \\
\hline Change $(n=4,897)$ & $+5.04(0.68)$ & $+5.73(0.86)$ & $+9.42(2.28)$ & .10 \\
\hline \multicolumn{5}{|c|}{ Letter-Digit Coding (number correct) } \\
\hline Baseline $(n=5,185)$ & $22.5(0.21)$ & $22.2(0.26)$ & $21.4(0.70)$ & .12 \\
\hline Change $(n=4,953)$ & $-1.63(0.14)$ & $-1.85(0.17)$ & $-2.41(0.46)$ & .08 \\
\hline \multicolumn{5}{|c|}{ Picture-Word Recall (number recalled) } \\
\hline \multicolumn{5}{|c|}{ Immediate } \\
\hline Baseline $(n=5,222)$ & $9.36(0.055)$ & $9.18(0.070)^{\S}$ & $8.93(0.185)^{\S}$ & $<.001$ \\
\hline Change $(n=5,004)$ & $-0.30(0.054)$ & $-0.49(0.069)^{\S}$ & $-1.00(0.184)^{\S * *}$ & $<.001$ \\
\hline \multicolumn{5}{|l|}{ Delayed } \\
\hline Baseline $(n=5,222)$ & $10.09(0.079)$ & $9.81(0.100)^{\S}$ & $9.33(0.264)^{\S}$ & $<.001$ \\
\hline Change $(n=5,004)$ & $-0.52(0.078)$ & $-0.76(0.099)$ & $-1.72(0.264)^{\S * *}$ & $<.001$ \\
\hline \multicolumn{5}{|l|}{ Barthel Index (score) } \\
\hline Baseline $(n=5,544)$ & $19.6(0.022)$ & $19.6(0.027)$ & $19.6(0.073)$ & 21 \\
\hline Change $(n=5,453)$ & $-0.51(0.055)$ & $-0.63(0.069)$ & $-0.72(0.185)$ & .06 \\
\hline \multicolumn{5}{|c|}{ Instrumental activities of daily living index (score) } \\
\hline Baseline $(n=5,544)$ & $13.4(0.030)$ & $13.4(0.038)$ & $13.4(0.101)$ & .30 \\
\hline Change $(n=5,454)$ & $-0.89(0.066)$ & $-1.20(0.083)^{\S}$ & $-1.18(0.223)$ & $<.001$ \\
\hline \multicolumn{5}{|c|}{ Mini-Mental State Examination (score) } \\
\hline Baseline $(n=5,479)$ & $28.0(0.046)$ & $27.8(0.058)^{\S}$ & $27.6(0.153)^{\S}$ & $<.001$ \\
\hline Change $(n=5,260)$ & $-0.14(0.058)$ & $-0.37(0.073)^{\S}$ & $-1.11(0.197)^{\S * *}$ & $<.001$ \\
\hline
\end{tabular}

${ }^{*} \mathrm{E}_{4}-$ includes $\mathrm{E}_{2 / 2}, \mathrm{E}_{2 / 3}, \mathrm{E}_{3 / 3} ; \mathrm{E}_{4}$ heterozygotes include $\mathrm{E}_{4 / 3}, \mathrm{E}_{4 / 2} ; \mathrm{E}_{4}$ homozygotes are $\mathrm{E}_{4 / 4}$. The number of subjects given is the maximum in each group. Data are adjusted for age, sex, country, education, history of vascular disease, history of myocardial infarction, history of diabetes mellitus, history of stroke or transient ischemic attack, smoking, use of antihypertensive medication, blood pressure, body mass index, low-density lipoprotein cholesterol, high-density lipoprotein cholesterol, triglyceride, and where applicable test version. Change score (last recorded result minus baseline result) was also adjusted for baseline test score and baseline test score and treatment allocation.

${ }^{\dagger} P$-value for test of heterogeneity across groups.

${ }^{\ddagger}$ Note a positive change in the Stroop test indicates a deteriorating performance.

${ }^{\S} \mathrm{E}_{4}$ heterozygotes or $\mathrm{E}_{4}$ homozygotes differ significantly from $\mathrm{E}_{4}-$.

${ }^{* *} \mathrm{E}_{4}$ homozygotes differ significantly from $\mathrm{E}_{4}$ heterozygotes.

Barthel or IADL indices. MMSE scores of $\mathrm{E}_{4}$ homozygotes were significantly lower than those with $\mathrm{E}_{4}-(P=.004)$, but the comparison between the former and $\mathrm{E}_{4}$ heterozygotes was not significant $(P=.11)$, although the means differed. Memory tests exhibited a trend toward stepwise reduction with $\mathrm{E}_{4}$ gene dosage. $\mathrm{E}_{4}$ homozygotes and heterozygotes had significantly lower scores than $\mathrm{E}_{4}-$, although possibly because of small subgroup size, the mean scores of homozygotes while tending to be lower than those of heterozygotes, were not significantly different $(P=.17$ for immediate memory; $P=.07$ for delayed memory).

The decline in performance on the Stroop and LetterDigit Coding tests was not significantly different in $\mathrm{E}_{4}-, \mathrm{E}_{4}$ heterozygotes, and $\mathrm{E}_{4}$ homozygotes (Table 3). For the immediate and delayed memory tests, the decrement in mean score for the $\mathrm{E}_{4}$ homozygotes was significantly greater than that for the heterozygotes $(P=.006$ for immediate; $P<.001$ for delayed memory). In turn, the decline for $\mathrm{E}_{4}$ heterozygotes was greater than that for $\mathrm{E}_{4}-(P=.001$ for immediate memory; $P=.004$ for delayed memory). A similar pattern was present for change in MMSE $\left(P<.001\right.$ for $\mathrm{E}_{4}$ homozygotes vs heterozygotes; $P<.001$ for heterozygotes vs $\left.E_{4}-\right)$. To test the effect of baseline MMSE score on the association between apolipoprotein $\mathrm{E}$ phenotype and decline in memory function, an average percentage decline in the scores for the immediate and delayed Picture-Word recall was computed. This combined variable gave significant differences for $\mathrm{E}_{4}$ homozygotes, $\mathrm{E}_{4}$ heterozygotes, and $\mathrm{E}_{4}-$ subjects in the whole cohort (Figure 1) and the apolipoprotein $\mathrm{E}$ effect persisted when subjects were restricted to those with MMSE scores of 26 to 30. A similar pattern was seen in subjects with baseline MMSE scores of 28 to 30, with an overall significant effect of phenotype; intergroup comparisons were at the border of significance, probably because of smaller numbers of patients.

\section{Influence of Lipoprotein Levels}

Examination of the association between lipoprotein plasma levels and cognitive function at baseline revealed generally weaker relationships than seen with apolipoprotein $\mathrm{E}_{4}$ status (Table 4). Results of the Picture-Word Recall tests were similar in all tertiles of LDL-C and HDL-C. The LetterDigit test was significantly related to LDL-C, with poorer 
Decline in Picture-Word Recall

(combined scores)

MMSE $26-30$

$(n=4,611)$
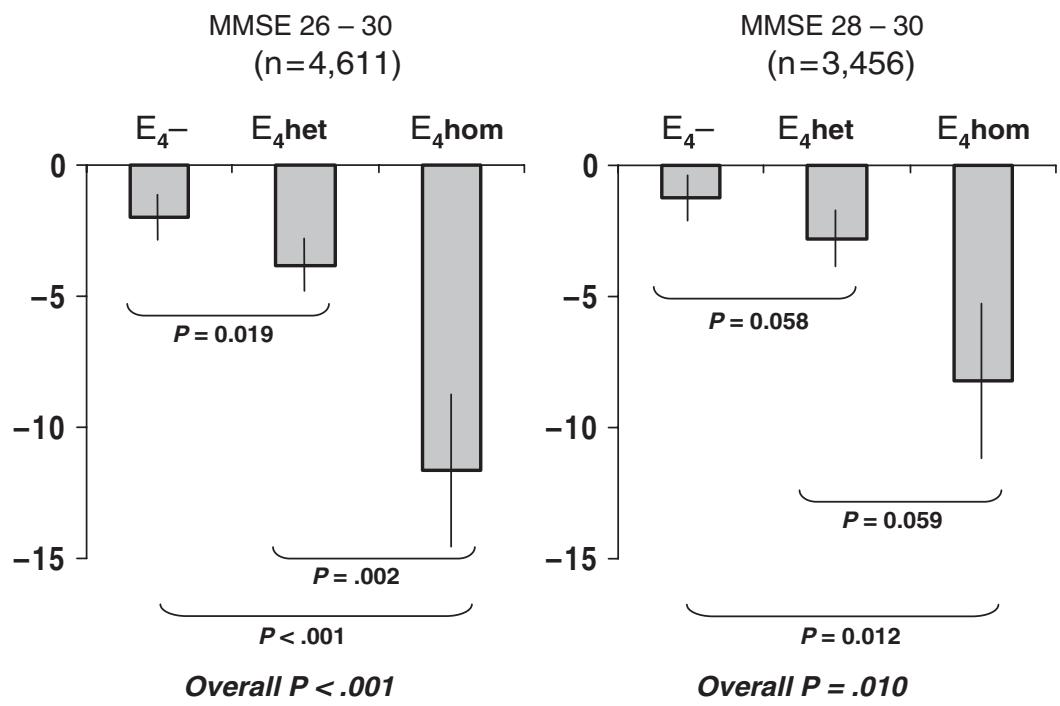

Figure 1. Decline in memory performance in apolipoprotein $\mathrm{E}_{4}$ homozygotes, $\mathrm{E}_{4}$ heterozygotes, and those without $\mathrm{E}_{4}$. An average percentage change was calculated from the results of the immediate and delayed Picture-Word Recall scores. The influence of apolipoprotein $\mathrm{E}_{4}$ status on this variable was examined in subjects with differing Mini-Mental State Examination (MMSE) score ranges at baseline. Least square mean changes (with standard errors) are given for $\mathrm{E}_{4}-$ subjects, $\mathrm{E}_{4}$ heterozygotes $\left(\mathrm{E}_{4}\right.$ het), and $\mathrm{E}_{4}$ homozygotes ( $\mathrm{E}_{4}$ hom). These were adjusted for the factors listed in the footnote to Table 1 and for treatment allocation. Significance levels are given for an overall effect and for intergroup comparisons. The number of evaluable subjects within a specific baseline MMSE range is provided (i.e., those with apolipoprotein E analysis and follow-up cognitive function scores available).

scores being seen in the lowest LDL-C tertile, and the Stroop test showed a trend in the same direction. The Barthel and IADL indices were significantly related to LDL-C level, with lower scores again being seen in the lowest tertiles. No significant association was observed between these indices and HDL-C.

Lipoprotein concentrations at baseline had no significant effect on change in cognitive function or decrease in score on the MMSE or the Barthel or IADL index (Table 4).

\section{DISCUSSION}

This study of the determinants of cognition in elderly adults found a marked effect of apolipoprotein $\mathrm{E}$ phenotype on memory performance that was apparent in the cross-sectional comparison at baseline and in the change over an average of 3.2 years of follow-up. Greater decline in memory in those with apolipoprotein $\mathrm{E}_{4}$ occurred irrespective of baseline levels of global cognitive function (as assessed by MMSE). This suggested that the phenotype has a general population effect, not just an influence in those with signs of impaired cognition. Furthermore, the association between apolipoprotein $\mathrm{E}_{4}$ and greater decline on the IADL index indicates that, at a population level, this phenotype has clinically important effects even in those who do not exhibit frank dementia. In contrast to the changes in memory performance, over this time scale, this genetic variation affected tests of the attention and processing cognitive domain to a much lesser extent. Plasma lipoprotein levels had limited influence on cognition at baseline and on its decline during follow-up.
After the initial reports of an association between Alzheimer's disease and apolipoprotein E phenotype, ${ }^{7}$ it has been demonstrated repeatedly that subjects possessing apolipoprotein $\mathrm{E}_{4}$, particularly homozygotes, have a high risk of developing dementia. ${ }^{10-15}$ The underlying mechanism is thought in part to be more beta-amyloid deposits in the presence of $\mathrm{E}_{4}$ than with other isoforms of the apolipoprotein, ${ }^{8,43}$ although it is increasingly clear that apolipoprotein E phenotype has multiple effects on neurobiology. ${ }^{21} \mathrm{Alz}$ heimer's disease, characterized by episodic memory loss, is likely to be the end result of a long subclinical degenerative process, and the question arises as to when and how apolipoprotein $\mathrm{E}_{4}$ contributes to this less-obvious pathology. As has been noted, ${ }^{11,13}$ early studies of the influence of apolipoprotein $\mathrm{E}_{4}$ on the rate of cognitive decline in the apparently normal population involved small numbers of subjects and included those with frank dementia or cognitive impairment at baseline or during subsequent evaluations. For example, one study ${ }^{44}$ reported a greater decrease in MMSE score and in information processing speed in elderly subjects with no initial cognitive impairment who were apolipoprotein $\mathrm{E}_{4}$ carriers; results for memory function were less clearcut, showing no significant drop. In that study, there was a fall of 0.8 to 1.4 points in the MMSE score, indicating that a number of subjects developed significant cognitive impairment during the assessment period. In the Cognitive Function and Ageing Study, apolipoprotein E phenotype was linked to risk of dementia (as determined according to MMSE score) in the cross-sectional survey, but no association was seen with incident dementia over 6 years. ${ }^{45}$ Results supporting a link between apolipoprotein $\mathrm{E}_{4}$ and memory impairment came from a study of 611 
Table 4. Comparison of Baseline Measures of Cognition and Cognitive Decline According to Tertile of Low-Density Lipoprotein Cholesterol (LDL-C) and High-Density Lipoprotein Cholesterol (HDL-C)

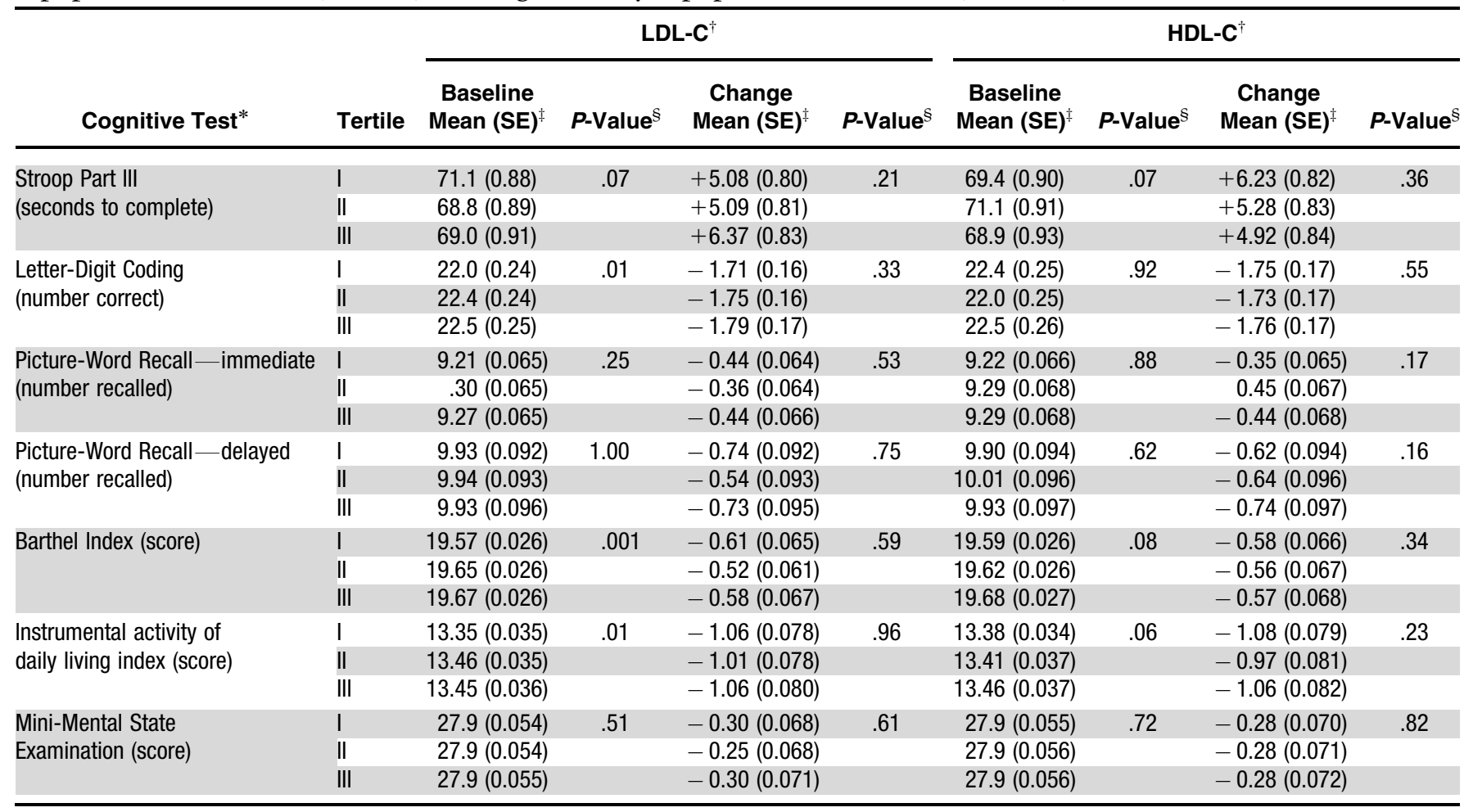

\footnotetext{
* The numbers for each test are shown in Table 1 for baseline models and Table 2 for change models.

${ }^{\dagger}$ Tertiles of LDL-C were I $<3.40$, II 3.40-4.10, III $>4.10 \mathrm{mmol} / \mathrm{L}$, tertiles of HDL-C were I $<1.10$, II 1.10-1.37, III $>1.37 \mathrm{mmol} / \mathrm{L}$.

${ }^{\S} P$-value for continuous measure of HDL-C or LDL-C (as appropriate).

${ }^{\ddagger}$ Least squares mean (standard error) for baseline result or for change (last recorded results minus baseline result) score adjusted for age, sex, country, education, history of vascular disease, history of myocardial infarction, history of stroke or transient ischemic attack, smoking, use of antihypertensive medication, blood pressure, body mass index, HDL-C or LDL-C (i.e., HDL-C was included in the model when LDL-C levels were tested and vice versa), plasma triglyceride, apolipoprotein $\mathrm{E}_{4}$, and where applicable test version. Change was also adjusted for baseline test score and treatment allocation.
}

elderly clergymen, in which it was seen that $\mathrm{E}_{4}$ had a morepronounced influence on the decline in episodic memory than on other cognitive domains. ${ }^{46}$ Again, the $16.7 \%$ incidence of clinically evident Alzheimer's disease may have influenced the result. More recently, in a report on the longterm follow-up of cognitive function in subjects aged 70 to 79 who were free of obvious dementia at baseline, apolipoprotein $\mathrm{E}_{4}$ was associated at 7 years but not at 3 years of followup with reduced memory function and decreased ability in other cognitive areas. ${ }^{47}$ Furthermore, in 840 cognitively normal elderly subjects followed for 3.5 years, apolipoprotein E phenotype and depression contributed to the appearance of mild cognitive impairment, apparently in an additive fashion. ${ }^{6}$ In contrast, in a population-based study ${ }^{13}$ in which subjects with dementia at baseline and at various stages of follow-up were excluded from the analysis, a greater preclinical decline in MMSE was present in participants who went on to develop dementia, but apolipoprotein $\mathrm{E}$ status had no influence on this change or on the rate of cognitive decline in those who were free of dementia throughout. Thus, debate continues about the influence of apolipoprotein $\mathrm{E}$ on cognition in the healthy aging population without dementia.

The present study has a number of features that should be borne in mind in assessing its conclusions. It followed a large cohort, and the majority of subjects had good cognitive function at baseline. Because of short follow-up, few developed dementia or poor general cognitive function.
(Mean decrease in MMSE score was 0.13 , and $89.3 \%$ of $\mathrm{E}_{4}+$ and $92.8 \%$ of $\mathrm{E}_{4}-$ subjects had MMSE scores $>24$ at their final assessment.) Dementia was not a formal studyspecific diagnosis but was recorded as an adverse event. On entry, subjects were selected to have a history of, or to be at risk of, a vascular event, and the results should be extrapolated to the general public in light of this design feature. In addition, half of the subjects were allocated to receive pravastatin, but the drug had no discernible effect on cognitive decline, and it is likely that treatment did not confound the result. ${ }^{27}$

Overall, a consistent influence of apolipoprotein $\mathrm{E}_{4}$ on memory function in the immediate and delayed recall tests was observed at baseline and during follow-up. This contrasted with the relative lack of influence of $\mathrm{E}_{4}$ on attention and processing (assessed by the Letter-Digit Coding test at baseline and follow-up and the Stroop test at follow-up). Furthermore, there was evidence of a gene dosage effect, with $\mathrm{E}_{4}$ homozygotes faring worse than heterozygotes. These results echo the findings of a meta-analysis of cross-sectional studies by, ${ }^{11}$ which concluded that, in the general aging population, the influence of apolipoprotein E genotype is small in magnitude and specific to certain domains of cognitive function. The findings of the current study, together with other, ${ }^{11,15}$ but not all, ${ }^{13,20}$ comparable observations, raise the possibility that apolipoprotein $\mathrm{E}_{4}$ is a determinant of the trajectory of memory loss (and consequent cognitive decline) in the elderly general population. 
Vascular dementia and Alzheimer's disease have a considerable degree of overlap in terms of neuropsychological impairments, although there is a tendency for vascular dementia to be associated with greater deficits in attention, speed of information processing, and executive function, ${ }^{48}$ whereas subjects with Alzheimer's disease have more problems with semantic memory. ${ }^{49,50}$ Thus, it was of interest to evaluate whether plasma lipoproteins potentially linked to vascular disease influenced specific domains of cognitive impairment. It was found that associations between lipoprotein levels and cognitive function tests were of borderline significance or not significant at baseline and during follow-up. The most notable observation was that low LDL-C levels independent of vascular disease history were associated with marginally poorer ADL and IADL scores; HDL-C exhibited a similar trend. Analogous findings were reported in the Leiden 85 Plus study, ${ }^{23}$ with low HDL-C being linked to poorer MMSE scores in subjects with and without a history of cardiovascular disease, although in that study, LDL-C showed no association with cognition. One possible explanation for the findings of the current study is that less-able elderly people are nutritionally compromised, and this leads to both lipoproteins being reduced, although a direct influence of lipoproteins on some cognitive aspects of disability cannot be excluded. Similar results were reported recently in a study that found no association between cholesterol or HDL-C and risk of dementia in a community-based study of cognitively intact elderly subjects. ${ }^{26}$

In conclusion, this large-scale cognition study embedded in a clinical trial revealed that, over an average 3.2-year period, the presence of the apolipoprotein $\mathrm{E}_{4}$ isoform was associated with greater decline in memory performance without apparently affecting attention or processing ability. The apolipoprotein E4 isoform was linked also to morepronounced deterioration in indices of ADLs and IADLs.

\section{ACKNOWLEDGMENTS}

This manuscript was prepared with the excellent secretarial assistance of Ms. Shelley Wilkie. We are indebted to Mrs. Dorothy Bedford and her technical staff for their help with the analysis of apolipoprotein E phenotype. The authors gratefully acknowledge the contribution of Dr. Peter Houx, who sadly died during the course of this study.

The PROSPER study group comprised

Executive Committee: (Glasgow) J. Shepherd (Chairman and Principal Investigator), S. M. Cobbe, I. Ford, A. Gaw, P. W. Macfarlane, C. J. Packard, D. J. Stott; (Leiden) G. J. Blauw (Principal Investigator), E. L. E. M. Bollen, A. M. Kamper, R. G. J. Westendorp; (Cork) M. B. Murphy (Principal Investigator), B. M. Buckley, M. Hyl, I. J. Perry.

Endpoint Committee: S. M. Cobbe (Chairman), J. W. Jukema, P. W. Macfarlane, A. E. Meinders, D. J. Stott, B. J. Sweeney, C. Twomey.

Data and Safety Monitoring Committee: W. V. Brown (Chairman), H. C. Diener, J. Feely, I. Ford (Nonvoting), T. Pearson, S. Pocock, P. A. van Zwieten.

Conflict of Interest: The study was supported by a grant from Bristol-Myers Squibb. This work was supported by a grant from the sponsor of the PROSPER trial. The editor in chief has determined that the authors have no conflict of interest related to this manuscript. CP has received research support or honoraria from AstraZeneca, Sanofi-Aventis, MSD, Schering Plough, and Glaxo SmithKline (GSK). MC has received research support or honoraria from AstraZeneca, GSK, and Sanofi-Aventis. RW has received research support from Bristol-Myers Squibb. JS has received research support or honoraria from AstraZeneca, GSK, MSD, Merck, and Schering-Plough. BB has received research support or honoraria from Pfizer, Bristol Myers Squibb, AstraZeneca, and Servier. AG has received research support from AstraZeneca. SC has received research support from AstraZeneca.

Author Contributions: All authors contributed to the interpretation of the results and drafting of the manuscript (CJP wrote the first draft). The executive committee (CJP, RGW, JS, GJB, MBM, ELEMB, BMB, SMC, IF, AG, MM, JWJ, AMK, PW McF, IJP, DJS, BJS, CT) had oversight of the design and conduct of PROSPER. MC undertook the apolipoprotein $\mathrm{E}$ analysis. HMM was responsible for statistical analysis of the cognitive decline findings. JJ oversaw interpretation of cognitive function tests.

Sponsor's Role: PROSPER was sponsored by BristolMyers Squibb Ltd and company personnel on the Executive Committee helped design and conduct the trial. The sponsor had no role in the present analysis.

\section{REFERENCES}

1. Dik MG, Deeg DJ, Bouter LM et al. Stroke and apolipoprotein E epsilon4 are independent risk factors for cognitive decline: A population-based study. Stroke 2000;31:2431-2436.

2. Haan MN, Shemanski L, Jagust WJ et al. The role of APOE epsilon4 in modulating effects of other risk factors for cognitive decline in elderly persons. JAMA 1999;282:40-46.

3. Launer LJ, Ross GW, Petrovitch $\mathrm{H}$ et al. Midlife blood pressure and dementia: The Honolulu-Asia aging study. Neurobiol Aging 2000;21:49-55.

4. Ott A, Stolk RP, van Harskamp F et al. Diabetes mellitus and the risk of dementia: The Rotterdam Study. Neurology 1999;53:1937-1942.

5. Podewils LJ, Guallar E, Kuller LH et al. Physical activity, APOE genotype, and dementia risk: Findings from the Cardiovascular Health Cognition Study. Am J Epidemiol 2005;161:639-651.

6. Geda YE, Knopman DS, Mrazek DA et al. Depression, apolipoprotein E genotype, and the incidence of mild cognitive impairment: A prospective cohort study. Arch Neurol 2006;63:435-440.

7. Saunders AM, Strittmatter WJ, Schmechel D et al. Association of apolipoprotein E allele epsilon 4 with late-onset familial and sporadic Alzheimer's disease. Neurology 1993;43:1467-1472.

8. Smith JD. Apolipoproteins and aging: Emerging mechanisms. Ageing Res Rev 2002;1:345-365.

9. Mahley RW, Huang Y. Apolipoprotein E: From atherosclerosis to Alzheimer's disease and beyond. Curr Opin Lipidol 1999;10:207-217.

10. Farrer LA, Cupples LA, Haines JL et al. Effects of age, sex, and ethnicity on the association between apolipoprotein E genotype and Alzheimer disease. A meta-analysis. APOE and Alzheimer Disease Meta Analysis Consortium. JAMA 1997;278:1349-1356.

11. Small BJ, Rosnick CB, Fratiglioni L et al. Apolipoprotein E and cognitive performance: A meta-analysis. Psychol Aging 2004;19:592-600.

12. Wilson RS, Schneider JA, Barnes LL et al. The apolipoprotein E epsilon 4 allele and decline in different cognitive systems during a 6-year period. Arch Neurol 2002;59:1154-1160.

13. Bunce D, Fratiglioni L, Small BJ et al. APOE and cognitive decline in preclinical Alzheimer disease and non-demented aging. Neurology 2004;63:816-821.

14. Small BJ, Graves AB, McEvoy CL et al. Is APOE-epsilon4 a risk factor for cognitive impairment in normal aging? Neurology 2000;54:2082-2088.

15. Reynolds CA, Prince JA, Feuk L et al. Longitudinal memory performance during normal aging: Twin association models of APOE and other Alzheimer candidate genes. Behav Genet 2006;36:185-194.

16. Swan GE, Lessov-Schlaggar CN, Carmelli D et al. Apolipoprotein E epsilon4 and change in cognitive functioning in community-dwelling older adults. J Geriatr Psychiatry Neurol 2005;18:196-201. 
17. Deary IJ, Whiteman MC, Pattie A et al. Apolipoprotein E gene variability and cognitive functions at age 79: A follow-up of the Scottish mental survey of 1932. Psychol Aging 2004;19:367-371.

18. Hofer SM, Christensen H, MacKinnon AJ et al. Change in cognitive functioning associated with apoE genotype in a community sample of older adults. Psychol Aging 2002;17:194-208.

19. Reitz C, Luchsinger JA, Tang MX et al. Stroke and memory performance in elderly persons without dementia. Arch Neurol 2006;63:571-576.

20. Qiu C, Winblad B, Fratiglioni L. Cerebrovascular disease, APOE epsilon4 allele and cognitive decline in a cognitively normal population. Neurol Res 2006;28:650-656

21. Huang Y. Apolipoprotein E and Alzheimer disease. Neurology 2006;66: S79-S85.

22. Persson J, Lind J, Larsson A et al. Altered brain white matter integrity in healthy carriers of the APOE epsilon4 allele: A risk for AD? Neurology 2006; 66:1029-1033.

23. van Exel E, de Craen AJ, Gussekloo J et al. Association between high-density lipoprotein and cognitive impairment in the oldest old. Ann Neurol 2002; 51:716-721.

24. Kivipelto M, Helkala EL, Laakso MP et al. Midlife vascular risk factors and Alzheimer's disease in later life: Longitudinal, population based study. BMJ 2001;322:1447-1451.

25. Wieringa GE, Burlinson S, Rafferty JA et al. Apolipoprotein E genotypes and serum lipid levels in Alzheimer's disease and multi-infarct dementia. Int J Geriatr Psychiatry 1997;12:359-362.

26. Li G, Shofer JB, Kukull WA et al. Serum cholesterol and risk of Alzheimer disease: A community-based cohort study. Neurology 2005;65: 1045-1050.

27. Shepherd J, Blauw GJ, Murphy MB et al. Pravastatin in elderly individuals at risk of vascular disease (PROSPER): A randomised controlled trial. Lancet 2002;360:1623-1630.

28. Houx PJ, Shepherd J, Blauw GJ et al. Testing cognitive function in elderly populations: The prosper study. Prospective Study of Pravastatin in the Elderly at Risk. J Neurol Neurosurg Psychiatry 2002;73:385-389.

29. Kalmijn S, Feskens EJ, Launer LJ et al. Cerebrovascular disease, the apolipoprotein e4 allele, and cognitive decline in a community-based study of elderly men. Stroke 1996;27:2230-2235.

30. Kalmijn S, Foley D, White L et al. Metabolic cardiovascular syndrome and risk of dementia in Japanese-American elderly men. The Honolulu-Asia Aging Study. Arterioscler Thromb Vasc Biol 2000;20:2255-2260.

31. O'Brien JT, Erkinjuntti T, Reisberg B et al. Vascular cognitive impairment. Lancet Neurol 2003;2:89-98.

32. Shepherd J, Blauw GJ, Murphy MB et al. The design of a prospective study of Pravastatin in the Elderly at Risk (PROSPER). PROSPER study group. PROspective Study of Pravastatin in the Elderly at Risk. Am J Cardiol 1999; 84:1192-1197.
33. The lipid research clinics program epidemiology committee. Plasma lipid distributions in selected North American populations: The lipid research clinics program prevalence study. Circulation 1979;60:427-439.

34. Havekes LM, de Knijff P, Beisiegel U et al. A rapid micromethod for apolipoprotein E phenotyping directly in serum. J Lipid Res 1987;28:455-463.

35. Folstein MF, Folstein SE, McHugh PR. "Mini-mental state". A practical method for grading the cognitive state of patients for the clinician. J Psychiatr Res 1975;12:189-198.

36. Brand N, Jolles J. Learning and retrieval rate of words presented auditorily and visually. J Gen Psychol 1985;112:201-210.

37. Houx PJ, Jolles J, Vreeling FW. Stroop interference: Aging effects assessed with the Stroop Color-Word Test. Exp Aging Res 1993;19:209-224.

38. Hobart JC, Lamping DL, Freeman JA et al. Evidence-based measurement: Which disability scale for neurologic rehabilitation? Neurology 2001;57: 639-644.

39. Mahoney FI, Barthel DW. Functional evaluation: The Barthel Index. Md State Med J 1965;14:61-65.

40. Lawton MP, Brody EM. Assessment of older people: Self-maintaining and instrumental activities of daily living. Gerontologist 1969;9:179-186.

41. Wolf PA, D'Agostino RB, Belanger AJ et al. Probability of stroke: A risk profile from the Framingham Study. Stroke 1991;22:312-318.

42. Shepherd J, Blauw GJ, Murphy MB et al. Pravastatin in elderly individuals at risk of vascular disease (PROSPER): A randomised controlled trial. Lancet 2002;360:1623-1630.

43. Weisgraber KH, Mahley RW. Human apolipoprotein E: The Alzheimer's disease connection. FASEB J 1996;10:1485-1494.

44. Dik MG, Jonker C, Comijs HC et al. Memory complaints and APOE-epsilon4 accelerate cognitive decline in cognitively normal elderly. Neurology 2001; 57:2217-2222.

45. Yip AG, Brayne C, Easton D et al. Apolipoprotein E4 is only a weak predictor of dementia and cognitive decline in the general population. J Med Genet 2002;39:639-643.

46. Wilson RS, Schneider JA, Barnes LL et al. The apolipoprotein E epsilon 4 allele and decline in different cognitive systems during a 6-year period. Arch Neurol 2002;59:1154-1160.

47. Bretsky P, Guralnik JM, Launer L et al. The role of APOE-epsilon4 in longitudinal cognitive decline: MacArthur Studies of Successful Aging. Neurology 2003;60:1077-1081.

48. O’Brien JT. Vascular cognitive impairment. Am J Geriatr Psychiatry 2006; 14:724-33.

49. Oosterman JM, Scherder EJ. Distinguishing between vascular dementia and Alzheimer's disease by means of the WAIS: A meta-analysis. J Clin Exp Neuropsychol 2006;28:1158-1175.

50. Poore QE, Rapport LJ, Fuerst DR et al. Word list generation performance in Alzheimer's disease and vascular dementia. Neuropsychol Dev Cogn B Aging Neuropsychol Cogn 2006;13:86-94. 